\title{
Pelatihan Literasi Sumber dan Bahan Belajar di Internet bagi Guru PAUD di Kecamatan Ngaglik, Sleman
}

\author{
Astri Hapsari ${ }^{1}$, Resnia Novitasari ${ }^{2}$, Hepi Wahyuningsih ${ }^{3}$ \\ 1, 2,3 Universitas Islam Indonesia
}

\begin{tabular}{|c|c|}
\hline ARTICLE INFO & ABSTRACT \\
\hline $\begin{array}{l}\text { Article History: } \\
\text { Received 06.09.2018 } \\
\text { Received in revised } \\
\text { form } 15.11 .2018 \\
\text { Accepted } 23.11 .2018 \\
\text { Available online } \\
\text { 21.12.2018 }\end{array}$ & $\begin{array}{l}\text { Learning media and resources are parts of Early Childhood Education } \\
\text { instructional design. Nowadays, learning media and resources include not } \\
\text { only natural environment but also cyber space in internet. However, some } \\
\text { Early Childhood Education teachers are not aware of the potential of using } \\
\text { these learning media and resources in their teaching practice. Therefore, an } \\
\text { in-house training of learning media and resources literacy was designed for } \\
\text { Early Childhood Education teachers in District of Ngaglik, Sleman Regency. } \\
\text { This training was attended by Rumah Anak Pintar Islami and Smart Child } \\
\text { Al-Mubarok Pre-Schools. The outcome of the training was better } \\
\text { understanding on learning media and resources in the internet which the } \\
\text { teachers can use in their teaching practice. }\end{array}$ \\
\hline
\end{tabular}

Keywords: Early Childhood Education, In-house Training, Internet, Learning Media, Learning Resources.

This is an open access article distributed under the terms of the Creative Commons Attribution 4.0 International License, which permits unrestricted use distribution, and reproduction in any medium, provided the original work is properly cited. @ 2018 Astri Hapsari, Resnia Novitasari, Hepi Wahyuningsih.

\section{PENDAHULUAN}

Kecamatan Ngaglik di Kabupaten Sleman terletak di wilayah utara Propinsi Daerah Istimewa Yogyakarta. Luas wilayah Kecamatan Ngaglik berkisar 3.852 Hektare dan terdiri atas 6 desa dengan jumlah penduduk sekitar 78.000 jiwa. Secara umum, wilayah ini telah memiliki fasilitas yang beragam, mulai dari fasilitas ekonomi, pendidikan, hingga layanan administratif. Akan tetapi di wilayah ini, untuk ruang lingkup Pendidikan Anak Usia Dini (PAUD), belum ada layanan bagi anak yang disediakan oleh pemerintah. Akses pendidikan bagi masa kanak-kanak awal ini banyak difasilitasi oleh swasta. Oleh sebab itu, ada beragam jenis dan rentang layanan mulai dari lembaga PAUD dengan fasilitas sederhana hingga sangat memadai.

Fokus pengabdian masyarakat pada kesempatan ini menyasar pada layanan PAUD yang diperuntukkan bagi kalangan masyarakat ekonomi menengah ke bawah. Terdapat dua mitra sekolah yang melayani anak-anak dari keluarga kurang mampu, yakni Kelompok Bermain Rumah Anak Pintar Islami (RAPI) di Desa Minomartani dan

${ }_{1}^{1}$ Corresponding author: Program Studi Pendidikan Bahasa Inggris, FPSB Universitas Islam Indonesia; Jl. Kaliurang KM-14,5, Sleman, DI Yogyakarta 55584; Email: astri.hapsari@uii.ac.id 
Kelompok Bermain Smart Child Al-Mubarrak di dusun Jetisbaran, Kecamatan Ngaglik, Kabupaten Sleman.

Berdasarkan hasil observasi dan wawancara dengan masing-masing kepala lembaga, tampak kendala yang mempengaruhi kegiatan belajar mengajar di PAUD sehari-hari. Selanjutnya, yang menjadi fokus permasalahan di kedua lembaga adalah masih terbatasnya pendidikan guru yang memenuhi kualifikasi pendidik. Pada Permendiknas Nomor 16 tahun 2007, dijelaskan bahwa pendidikan untuk guru adalah pada level S1 (Sarjana). Sementara, sebagian guru di kedua lembaga tersebut kebanyakan berpendidikan di tingkat SMA. Kalaupun sarjana, sebagian tidak menempuh jenjang S1 PAUD.

Keterbatasan dari sisi pendidikan ini juga berimbas pada proses belajar mengajar. Pada umumnya guru di Kelompok Bermain RAPI telah mulai bervariasi dalam mempersiapkan Rancangan Kegiatan Harian (RKH). Mereka memanfaatkan sumber belajar di sekitarnya untuk menunjang kegiatan belajar mengajar, misalnya: belajar di sawah dekat desa tersebut. Meskipun demikian, guru-guru masih terbatas kemampuannya dalam penerapan teknologi informasi, baik sebagai ketrampilan pedagogik maupun penunjang profesional. Padahal, ada beragam informasi untuk meningkatkan pengetahuan dan ketrampilan guru yang dapat diakses melalui internet misalnya. Pemerintah juga telah menyediakan website khusus bagi guru PAUD (anggunpaud.kemdikbud.go.id) yakni ruang berbagi guru PAUD dalam jaringan. Pelibatan teknologi informasi dalam kegiatan belajar mengajar juga menjadi prioritas lembaga, sebab tidak dapat dipungkiri, literasi teknologi informasi menjadi satu kebutuhan krusial. Selain untuk kompetensi guru, juga menumbuhkan pemahaman anak akan penguasaan teknologi informasi di era digital.

Media dan sumber belajar adalah bagian yang tidak terpisahkan dalam desain instruksional kurikulum pendidikan baik di kurikulum pendidikan anak usia dini, kurikulum pendidikan dasar, kurikulum pendidikan menengah, maupun kurikulum pendidikan tinggi. Secara definitif, media adalah alat saluran komunikasi (Heinich, Molenda, Russell, \& Smaldino, 2002). Sementara itu sumber belajar menurut Association of Educational Communication and Technology (AECT) (1977) memiliki arti yang lebih luas dari media pembelajaran, yaitu: semua sumber yang dapat dipakai oleh peserta didik (dalam hal ini guru PAUD) sebagai suatu sumber belajar tersendiri atau dalam kombinasi untuk memperlancar belajar terdiri dari message (pesan), people (orang), materials (bahan), device (alat), technique, setting (lingkungan).

Kemp dan Dayton (1985) memaparkan manfaat media dalam pendidikan, yaitu: 1) penyampaian pesan pembelajaran dapat lebih terstandar; 2) pembelajaran dapat lebih menarik; 3) pembelajaran menjadi lebih interaktif dengan menerapkan teori belajar; 4) waktu pelaksanaan pembelajaran diperpendek; 5) kualitas pembelajaran dapat ditingkatkan; 6) proses pembelajaran dapat berlangsung kapan dan dimana pun diperlukan; 7) sikap positif siswa terhadap materi pembelajaran serta proses pembelajaran dapat ditingkatkan; 8) peran guru ke arah positif. Sementara Zaman (2014) menjelaskan pentingnya sumber belajar bagi anak didik usia dini antara lain beragam sumber belajar akan: 1) memberikan kesempatan untuk mendapatkan pengetahuan dan memperkaya wawasan anak untuk menyalurkan keingintahuannya terhadap banyak hal; 2) meningkatkan kemampuan anak dalam berbahasa; 3) mengenalkan anak pada lingkungan sekaligus mengenal kekuatan dan kelemahan dirinya; 4) menumbuhkan motivasi belajar anak sehingga perhatian meningkat; 5) memungkinkan anak untuk 
mencapai tujuan pembelajaran dengan baik; dan 6) mendukung siswa untuk melakukan kegiatan belajar.

Dalam hal pemanfaatan media dan sumber belajar PAUD juga dipengaruhi perkembangan teknologi informasi dan komunikasi (TIK). Media dan sumber belajar semakin beragam dan tidak hanya terbatas pada lingkungan alam sekitar, tetapi juga ruang siber (cyber space) di internet (jaringan komputer global yang menyediakan beragam fasilitas informasi dan komunikasi). Masih minimnya pemahaman guru tentang aplikasi teknologi informasi dalam pengembangan profesionalisme dan kegiatan belajar mengajar mendorong tim pengabdian untuk memberikan pelatihan melek literasi. Diharapkan setelah mengikuti pelatihan para guru dalam memberikan materi pada anak-anak dapat menggunakan internet sebagai sumber referensi.

\section{METODE PELAKSANAAN}

Metode pelatihan yang digunakan untuk memperkenalkan media dan sumber belajar adalah in-house training yang bertujuan meningkatkan pemahaman serta kesadaran guru PAUD mengenai media dan sumber belajar yang dapat dimanfaatkan di internet. Pelatihan ini diikuti oleh guru-guru PAUD dari Kelompok Bermain (KB) Rumah Anak Pintar Islami dan KB Smart Child Al-Mubarok. Pelatihan menggunakan metode active learning dengan langkah-langkah kerja sebagai berikut:

1) Pembagian lembar pre-test evaluasi:

Setiap peserta diminta mengisi pre-test evaluasi secara mandiri dan dalam waktu yang ditentukan.

2) Fasilitator menjelaskan tentang konsep media dan sumber belajar di kurikulum PAUD dan literasi media untuk guru PAUD. Sesi diskusi dan tanya jawab juga dimungkinkan dalam sesi ini.

3) Fasilitator meminta peserta untuk bekerja dalam 2 kelompok untuk menggunakan 2 laptop yang tersedia. Kemudian, fasilitator memberi beberapa tautan media dan sumber belajar di internet. Tugas peserta adalah menjelajahi tautan tersebut.

4) Setelah itu, masing-masing peserta diberi lembar kerja yang berisi kompetensi dasar dan indikator pencapaian kompetensi dalam kurikulum PAUD yang berbeda-beda secara acak.

5) Masing-masing peserta memilih media dan sumber belajar untuk memenuhi indikator pencapaian kompetensi dari kompetensi dasar yang ditugaskan pada lembar kerja.

6) Pembagian lembar post-test evaluasi:

Setiap peserta diminta mengisi post-test evaluasi secara mandiri dan dalam waktu yang ditentukan.

\section{HASIL DAN PEMBAHASAN}

Pelatihan yang dilakukan untuk mendorong kompetensi literasi digital pada pendidik PAUD telah berjalan. Jumlah peserta pelatihan sebanyak tujuh orang pendidik dari kedua lembaga PAUD tersebut. Sebagian besar masih awam dalam memahami penggunaan internet sebagai bahan sumber belajar. Ada peserta yang belum familiar dengan penggunaan komputer dan internet. Pada umumnya, pengenalan teknologi 
dalam pembelajaran hanya sebatas mengenalkan berbagai jenis alat komunikasi pada anak usia dini serta fungsinya. Penggunaan laman pencari seperti Google juga masih terbatas. Sebagian besar guru telah memanfaatkan media sosial seperti laman Youtube, Whatsapp, maupun Facebook. Namun demikian, pada umumnya, pendidik belum memanfaatkan hal tersebut untuk aktivitas pembelajaran dengan anak. Ada pendidik yang telah melatih anak melihat dan mendengarkan ketika mempelajari huruf hijaiyah. Akan tetapi, hal tersebut belum menjadi bagian dari rancangan kegiatan pembelajaran sehari-hari.

Pada saat pelaksanaan pelatihan, fasilitator memberikan terlebih dahulu materi tentang berbagai alternatif pencarian sumber bahan ajar melalui internet. Kegiatan diskusi dan ceramah ini diberikan di awal kegiatan. Selanjutnya, pendidik diminta berpasangan untuk mencoba berbagai situs pendukung Pendidikan Anak Usia Dini, untuk mengakses materi yang dapat meningkatkan pengetahuan dan ketrampilan. Kemudian, dalam pasangan tersebut, peserta diminta untuk memilih bahan ajar dan kegiatan di internet yang sesuai dengan Rencana Pembelajaran Harian di PAUD tersebut. Setelah itu, dilakukan presentasi secara berpasangan pada masing-masing guru.

Luaran yang dihasilkan pada pelatihan ini adalah adanya lembar Rencana Pembelajaran Harian yang telah terintegrasi dengan pengembangan teknologi. Kemudian, dua orang guru telah berhasil membuat email google dan menjawab undangan di Google classroom. Tujuan dari penggunaan Google classroom adalah agar kelompok guru di PAUD tersebut dapat saling mengakses sumber bahan ajar secara kolektif.

Selain itu, ada penambahan pengetahuan terkait akses sumber materi berbasis teknologi untuk menunjang pembelajaran anak. Berdasarkan hasil tes pemahaman sebelum dan sesudah kegiatan, pada umumnya ada peningkatan skor. Hal tersebut mengindikasikan bertambahnya pengetahuan guru mengenai literasi digital yang disampaikan.

Tabel 1. Hasil Pencapaian Pelatihan Pemanfaatan Media dan Sumber Belajar di Internet

\begin{tabular}{llcc}
\hline No & Nama Peserta & Sebelum Pelatihan & Setelah Pelatihan \\
\hline 1 & Guru 1 & 2 & 4 \\
2 & Guru 2 & 2 & 3 \\
3 & Guru 3 & 3 & 3 \\
4 & Guru 4 & 3 & 2 \\
5 & Guru 5 & 2 & 3 \\
6 & Guru 6 & 1 & 3 \\
7 & Guru 7 & 1 & 1 \\
\hline
\end{tabular}

Dari hasil pengisian lembar refleksi setelah kegiatan, guru menyampaikan beberapa pengetahuan baru yang dikuasai, yakni: (1) Mengetahui penggunaan web dengan link Anggun PAUD, Canva, Pinterest untuk menunjang pembelajaran di kelas supaya lebih menarik, (2) Memahami cara untuk memaksimalkan peran internet dan situs pencarian dalam pembelajaran, (3) Mengetahui cara membuat presentasi menggunakan power point, (4) Mengetahui sumber-sumber internet untuk mengunduh gambar, lagu, video, maupun flashcard. Berdasarkan capaian tersebut, tampak bahwa ada berbagai pengetahuan baru yang didapatkan oleh guru. 
Evaluasi dilakukan setelah tiga minggu pelaksanaan kegiatan. Hasilnya adalah sebagian guru telah menggunakan Youtube untuk mengunduh video pembelajaran serta mengaktifkan Google classroom. Namun demikian, akses ke sumber pembelajaran lainnya belum berjalan maksimal, sebab masih terkendala dengan persiapan kedua lembaga dalam persiapan akreditasi.

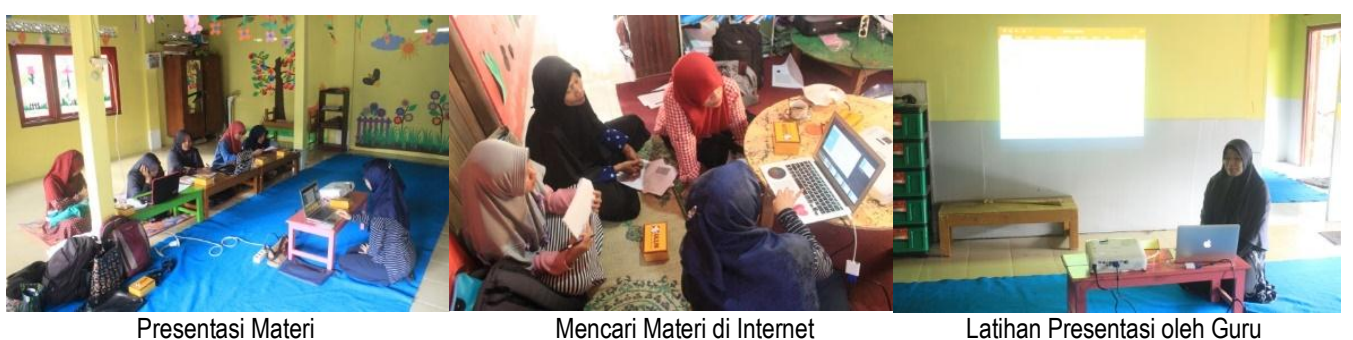

Gambar 1. Dokumentasi Pelaksanaan Kegiatan

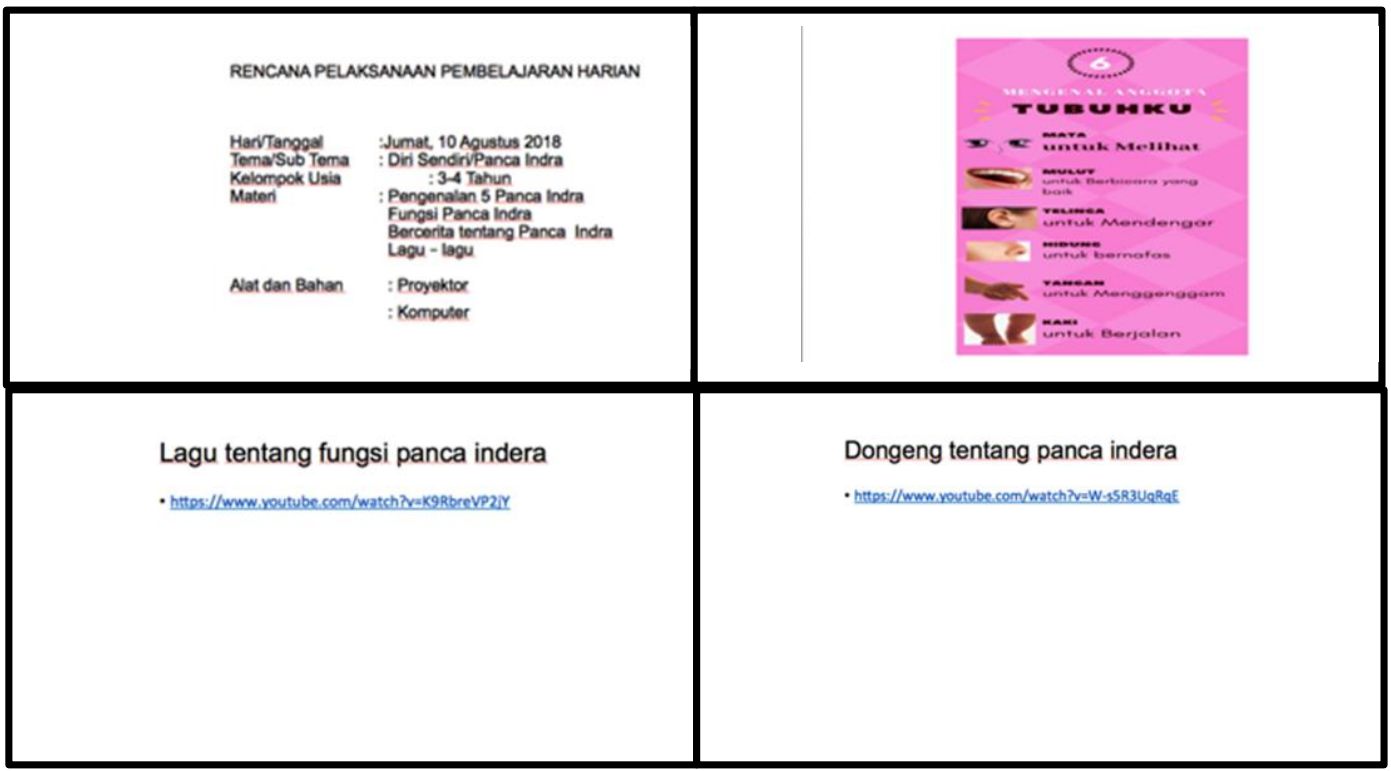

Gambar 2. Hasil Latihan Pembuatan RPPH menggunakan Media dan Sumber Belajar di Internet

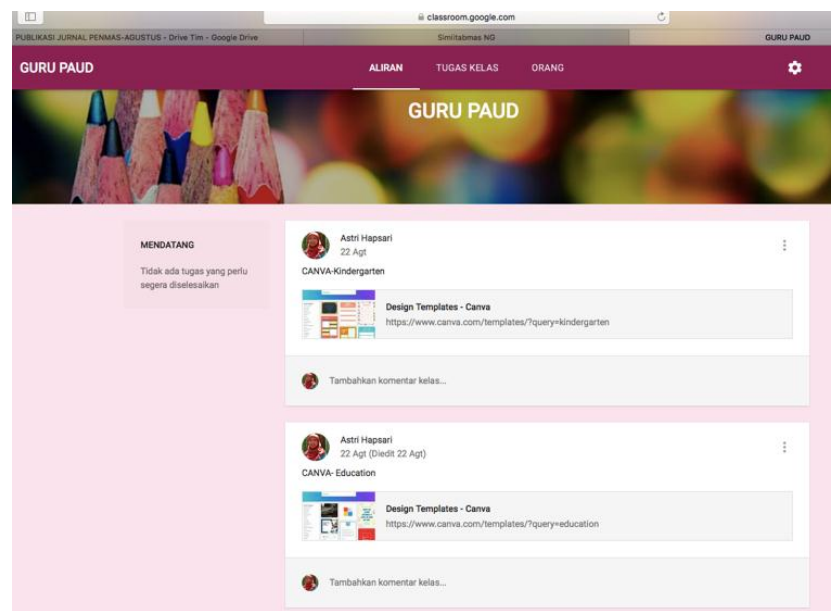

Gambar 3. Google Classroom yang Telah Diikuti oleh Guru PAUD 
Hasil dari proses pelatihan ini terhadap pendidik PAUD menumbuhkan pengetahuan baru tentang pemanfaatan literasi internet secara optimal dalam kegiatan belajar mengajar. Hal ini selaras dengan kajian dari Hardiyana (2016) bahwa penambahan ketrampilan penguasaan teknologi informasi pada guru PAUD akan membantu mereka dalam mengembangkan inovasi dan kreativitas dalam pembelajaran. Selain itu, Burnett (2010) juga menegaskan bahwa ada tiga cara dalam literasi digital di setting PAUD, yakni sebagai salah satu penghantar literasi digital pada anak, sarana untuk berinteraksi di dunia maya, serta media untuk meningkatkan pemahaman pada pembelajaran. Pengetahuan dan ketrampilan yang didapatkan oleh guru pada kegiatan pelatihan ini, menunjukkan adanya literasi digital dengan menggunakan variasi sumber bahan ajar. Selain itu, juga bertambah kemampuan guru dalam berinteraksi di dunia maya selain menggunakan media sosial. Misalnya saja interaksi dalam Google classroom. Selanjutnya juga memunculkan berbagai alternatif media bahan ajar.

\section{SIMPULAN}

Media dan sumber belajar di internet dapat menjadi variasi materi mengajar bagi guru PAUD. Dengan melimpahnya materi di internet, guru PAUD akan terbantu apabila memiliki platform untuk mengumpulkan tautan-tautan link media dan sumber belajar secara online. Hasil dari proses pelatihan ini terhadap pendidik PAUD menumbuhkan pengetahuan baru tentang pemanfaatan literasi internet secara optimal dalam kegiatan belajar mengajar.

\section{REFERENSI}

Burnett, C. (2010). Technology and literacy in early childhood educational settings: a review of research. Journal of Early Childhood Literacy, 10(3), 247-270.

Kemp, J. E., \& Dayton, D.K. (1985). Planning and producing instructional media. New York: Harper \& Row.

Hardiyana, A. (2016). Optimalisasi pemanfaatan teknologi informasi dan komunikasi dalam pembelajaran PAUD. Awlady: Jurnal Pendidikan Anak, 2(1), 1-12.

Seels, B.B. \& Glasgow, Z. (1990). Exercises in instructional design. Columbus: Merril Publishing Company.

Wijana, W.D. (2014). Modul 1: Konsep pendidikan anak usia dini. Tangerang Selatan: Universitas Terbuka.

Wiryokusumo, I., \& Mustaji. (1985). Pengelolaan sumber belajar. Surabaya: IKIP Surabaya University Press.

Zaman, B., \& Eliyawati, C. (2010). Bahan ajar pendidikan profesi guru (PPG): Media pembelajaran anak usia dini. Bandung: Universitas Pendidikan Indonesia.

Zaman, B. (2014). Media dan sumber belajar PAUD. Tangerang Selatan: Universitas Terbuka. 